\title{
25 Research Soure

\section{Modification of Magnetic Graphene Oxide By An Earth-Friendly Deep Eutectic Solvent To Preconcentrate Ultratrace Amounts Pb(II) In Oil Seeds}

Melika Hejazi Khah

University of Tehran

Parastoo Jamshidi ( $\sim$ parastoo.jamshidi@ut.ac.ir)

University of Tehran

\section{Research Article}

Keywords: Deep eutectic solvent, MSPE, Pb(II), Oil seeds, Flame atomic absorption spectroscopy

Posted Date: November 3rd, 2021

DOI: https://doi.org/10.21203/rs.3.rs-1034161/v1

License: (c) (1) This work is licensed under a Creative Commons Attribution 4.0 International License. Read Full License 


\section{Abstract}

The aim of this article is presenting an earth-friendly deep eutectic solvent (DES) to preconcentrate ultratrace amounts of $\mathrm{Pb}$ (II) prior to its quantification by flame atomic adsorption spectroscopy. The synthesis of adsorbent started by preparing graphene oxide according to the modified Hammer's method, followed by magnetization by $\mathrm{Fe}_{3} \mathrm{O}_{4}$ nanohemispheres. Magnetic graphene oxide was dispersed in a mixture of $\mathrm{LiCl}$ and urea at $60^{\circ}$ via ultrasonication. All the materials are environmentally-friendly and the preparation strategy is energy efficient. X-ray diffraction, scanning electron microscopy, alternating gradient force magnetometer and Fourier-transform infrared spectroscopy were applied to characterize the products. Graphene oxide has a large surface area and could be functionalized with DESs through $\pi-$ $\pi$ interaction and electrostatic force. Urea has active negative sites, which garb heavy metals due to the interaction between negative and positive agents. Accordingly, this adsorbent (UreaLiCl-mGO) could be offered as a capable adsorbent to preconcentrate ultratrace amounts of $\mathrm{Pb}(\mathrm{II})$. Conditions were optimized, and under the optimum situation, (a) limit of detection of $99 \times 10^{-8} \mathrm{~g} \mathrm{~L}^{-1}$, (b) relative standard deviation $(n=5)$ of $1.3 \%$, (c) preconcentration factor of 100 (d) linearity of dynamic range of $5.0 \times 10^{-6}-$ $23 \times 10^{-6} \mathrm{~g} \mathrm{~L}^{-1}$, (e) durability of 6 months and (f) reusability of 7 times prove applicability of the adsorbent. The tests of selectivity, effect of interference ions, swelling property, isotherm of adsorption, kinetic of adsorption and thermodynamic of adsorption were completely investigated. Four different oil seeds were successfully applied as real samples.

\section{Introduction}

Lead is a hazardous heavy metal, which reasons many health problems such as poisoning metabolic, inhibiting enzymes, damaging nervous connections, being replaced with calcium in bones and causing blood and brain disorders $[1,2]$. Therefore, presenting applicable analytical methods to quantify its ultratrace concentrations are vital [3]. Magnetic solid phase extraction (MSPE) - a novel classification of solid phase extraction - is an authentic analytical technique. In this method, analyte was adsorbed onto a magnetic adsorbent, so filtration and centrifuge are substituted by applying an external magnetic field [4-8].

Using nanomaterials is an actual policy to advance the proficiency of MSPE [9]. Magnetic nanostructures have stronger magnetic properties, leading to simplify separation steps and decreasing separation time. Moreover, nanoadsorbents have more surface area in comparison with non-nanomaterials; since, these adsorbents have more affinity toward analyte(s), as well as being functionalized by other agents [10-12]. Deep eutectic solvent (DES) is a new classification of ionic liquid groups, but has lower lattice energy and lower melting points. Researchers suggest many types of DESs, but one of them is mixtures of metal halides and urea with melting points of $<80$. These materials are safe, inexpensive, accessible and green. Therefore, the final product is environmentally-friendly and the method of preparation is energy efficient [13-16]. 
Up to now, a variety of DES have been applied to preconcentrate contaminants. A dispersive liquid-liquid microextraction based on DES, including choline chloride and three different hydrogen bond donor ethylene glycol, oxalic acid or urea was applied to preconcentrate $\mathrm{Pb}(\mathrm{II})$ and $\mathrm{Cd}(\mathrm{II})$ form various water samples [17]. In another example, methadone, $\mathrm{Cd}(\mathrm{II}), \mathrm{Pd}(\mathrm{II}), \mathrm{Ni}(\mathrm{II})$ and $\mathrm{Cu}(\mathrm{II})$ in biological samples were detected via liquid-liquid extraction method based on DESs [18, 19]. In addition, Shokuhi Rad et al. proposed a mixture of choline chloride and 4-boromo phenol as a DES to preconcentrate $\mathrm{Ni}(\mathrm{II})$. Gul Kazi et al. preconcentrated $\mathrm{Pb}$ (II) and $\mathrm{Cd}$ (II) from cosmetic sample based on mixing $\mathrm{ZnCl}_{2}$ and $\mathrm{CH}_{3} \mathrm{CONH}_{2}$ [20].

In this article, a DES of $\mathrm{LiCl}$ and urea was loaded onto magnetic graphene oxide ( $\mathrm{mGO}$ ) and then the adsorbent (UreaLiCl-mGO) was applied as a magnetic adsorbent to quantify ultratrace amounts of $\mathrm{Pb}(\mathrm{II})$ in oil seeds samples. Synthesis procedure is very facile, fast, low-temperature, low-pressure and environment-friendly. X-ray diffraction, Fourier transform infrared spectroscopy, scanning electron microscopy and alternating gradient force magnetometer check the crystallinity, loading DES, morphology and magnetic property, respectively. The preconcentration conditions were optimized and analytical figures of merits were reported. A flame atomic adsorption spectrometer measured the concentrations of analyte. Isotherm, adsorption kinetic and adsorption thermodynamics showed the adsorption mechanism of $\mathrm{Pb}(\mathrm{II})$ onto UreaLiCl-mGO.

\section{Experimental}

\subsection{Apparatus}

A flame atomic absorption spectrometer (FAAS; Varian Spectra AA-400 (www.varianinc.com, California, United States)), equipped with a deuterium background correction and an air-acetylene burner, determined the concentration of the analyte. The instrument set in PROMT mode at $217 \mathrm{~nm}$ and a spectral bandwidth of $1 \mathrm{~nm}$. A digital pH meter (Metrohm - 692 (www.metrohm-ag.com, Herisau, Switzerland)), equipped with a glass combination electrode, adjusted $\mathrm{pH}$. An ultrasonic bath (Elma, S40; www.elma.com, Singen, Germany) was employed for synthesis of UreaLiCl-mGO. A powder X-ray diffraction (XRD; Philips - PW1730 (www.panalytical.com, Eindhoven, Netherland)) characterized the crystallinity of the products. $1.2 \mathrm{~kW}$ Cu source was used to produce $X$-ray, $2 \theta$ ranged from $10^{\circ}$ to $80^{\circ}$, scan step and step time were $0.05^{\circ}$ and 1 second, respectively. A field emission scanning electron microscopic (FE-SEM; TESCAN-MIRA III (www.tescan.com, Czech Republic)) visualized the morphology $\mathrm{mGO}$ and UreaLiCl-mGO. An alternative gradient force magnetometer (AGFM; Meghnatis Daghigh Kavir Company (https://nano.kashanu.ac.ir, Kashan, Iran)) measured magnetic properties in an applied magnetic field sweeping between $\pm 10,000$ Oe. ABB Bomem MB100 IR spectrometer recorded FT-IR spectra (http://new.abb.com, Zürich, Switzerland).

\subsection{Reagent and solution}

All the reagents were of analytical grade. The salts for preparing $\mathrm{Pb}(\mathrm{II})$ standard $\left(1.0 \times 10^{-3} \mathrm{~g} \mathrm{~L}^{-1}\right)$ and testing interference ions, $\mathrm{NaNO}_{3}$, graphite powder, $\mathrm{KMnO}_{4}, \mathrm{H}_{2} \mathrm{SO}_{4}, \mathrm{H}_{2} \mathrm{O}_{2}, \mathrm{HNO}_{3}, \mathrm{FeCl}_{2} .4 \mathrm{H}_{2} \mathrm{O}, \mathrm{FeCl}_{3} .6 \mathrm{H}_{2} \mathrm{O}$, 
$\mathrm{NH}_{4} \mathrm{OH}$, urea and LiCl were procured from Merck Company (www.merck.de, Darmstadt, Germany). Ultrahigh purity from a Milli-Q system water was used to prepare sample solutions.

\subsection{Synthesis of UreaLiCl-mGO}

Firstly, GO was synthesized according to the modified Hummer's procedure. Graphite powder (1.0 g), $\mathrm{NaNO}_{3}(1.0 \mathrm{~g})$ and $\mathrm{H}_{2} \mathrm{SO}_{4}(23 \mathrm{~mL})$ were mixed together in an ice bath and stirred 15 minutes, followed by adding $\mathrm{KMnO}_{4}(3.0 \mathrm{~g})$ at $20^{\circ} \mathrm{C}$ and stirring for two hours. The mixture was kept at $35^{\circ} \mathrm{C}$ for one hour and then deionized water $(45 \mathrm{~mL})$ was slowly added to the mixture. The suspension was re-stirred at $98^{\circ} \mathrm{C}$ for 30 minutes. Afterwards the temperature was fixed at $25^{\circ} \mathrm{C}$ to add deionized water $(140 \mathrm{~mL})$ and $\mathrm{H}_{2} \mathrm{O}_{2}$ $(30 \%, 12 \mathrm{~mL})$ and then the materials were stirred for 2 hours. The product was filtered, eluted with water, eluted with $\mathrm{HCl}(5 \%)$ and dried at $60^{\circ} \mathrm{C}[21]$.

Secondly, magnetization was applied, based on the Massart's method. $\mathrm{FeCl}_{3} \cdot 6 \mathrm{H}_{2} \mathrm{O}(2.5 \mathrm{~g})$ and $\mathrm{FeCl}_{2}$. $4 \mathrm{H}_{2} \mathrm{O}\left(9.0 \times 10^{-1} \mathrm{~g}\right)$ were dissolved in deionized water $(100 \mathrm{~mL})$. GO $\left(1.0 \times 10^{-1} \mathrm{~g}\right)$ was dispersed in the iron solution through 15 minutes sonication, followed by adding $\mathrm{NH}_{4} \mathrm{OH}(25 \%, 15 \mathrm{~mL})$ drop by drop under nitrogen atmosphere. After stirring for 12 hours, the product was magnetically separated, eluted by distilled water and dried at $80^{\circ} \mathrm{C}[21]$.

Finally, mGO was modified by DES. A mixture of Urea $\left(5.0 \times 10^{-2} \mathrm{~g}\right)$ and $\mathrm{LiCl}\left(5.0 \times 10^{-2} \mathrm{~g}\right)$ was heated in a sand bath at $60^{\circ} \mathrm{C}$. After obtaining a colorless liquid, $\mathrm{mGO}\left(5.0 \times 10^{-2} \mathrm{~g}\right)$ was dispersed into the DES via one hour sonication. The final product (UreaLiCl-mGO) was washed with distilled water and then cooled to room temperature [13].

\subsection{General procedure}

UreaLiCl-mGO $\left(1.0 \times 10^{-2} \mathrm{~g}\right)$ was added to an aqueous sample solution containing $\mathrm{Pb}(\mathrm{II})(50 \mathrm{~mL}, 5.0 \times$ $\left.10^{-5} \mathrm{~g} \mathrm{~L}^{-1}\right)$ at the $\mathrm{pH}$ of $5 \pm 0.5$. The sample was shaken for 15 minutes, and then an external magnet gathered the adsorbent. The adsorbed $\mathrm{Pb}(\mathrm{II})$ was eluted by $\mathrm{HNO}_{3}\left(0.5 \mathrm{~mL}, 2 \mathrm{~mol} \mathrm{~L}{ }^{-1}\right)$ after 4 minutes sonication. FAAS determined the eluted concentration of $\mathrm{Pb}(\mathrm{II})$ ions.

\subsection{Sample preparation}

Sesame, hemp, sunflower seeds and grapeseed were bought from local supermarkets in Tehran. They were cleaned with double-distilled water and dried at $50^{\circ} \mathrm{C}$. The cooled samples $\left(1.0 \times 10^{-1} \mathrm{~g}\right)$ were immersed in $\mathrm{HNO}_{3}(15 \mathrm{~mL}, 65 \%)$ for 48 hours. The samples were heated $\left(90^{\circ} \mathrm{C}\right)$, followed by adding $\mathrm{H}_{2} \mathrm{O}_{2}$ $(20 \mathrm{~mL}, 30 \%)$. The samples were re-heated $\left(150^{\circ} \mathrm{C}\right)$ for 10 minutes until ceasing the evolution of fumes. This procedure was repeated until obtaining a clear transparent solution. The samples were cooled to room temperature, lttered with sieve paper and filled to the mark in a $200 \mathrm{~mL}$ falcon with distilled water.

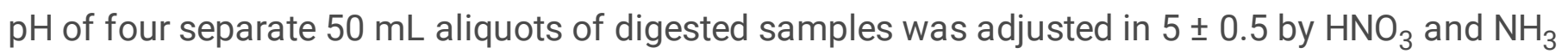
solutions. The general procedure was applied as mentioned in section of general procedure. Matrix 
spiking with standard of $\mathrm{Pb}(\mathrm{II})\left(1.0 \times 10^{-5}, 5.0 \times 10^{-5}\right.$ and $\left.15 \times 10^{-5} \mathrm{~g} \mathrm{~L}^{-1}\right)$ was applied to assess the matrix effects.

\section{Result And Discussion 3.1 Characterization}

FT-IR analyses confirm that DES was successfully loaded onto mGO (Fig. 1). The FT-IR spectrum of mGO was shown in the black spectrum. The stretching frequencies of the $0-\mathrm{H}$ band is illustrated at $3121 \mathrm{~cm}^{-1}$ [22]. The absorbance at $1586 \mathrm{~cm}^{-1}$ is attributed to aromatic $\mathrm{C}=\mathrm{C}$. Stretching vibration of $\mathrm{C}-\mathrm{O}$ groups caused duple bonds at 1117 and $1042 \mathrm{~cm}^{-1}$ [22]. Peaks lower than 700 characterizes bond of $\mathrm{Fe}-0$ [23]. The green spectrum shows the FT-IR spectrum of UreaLiCl-mGO. The bands of $3400 \mathrm{~cm}^{-1}, 1600 \mathrm{~cm}^{-1}$ and $1400 \mathrm{~cm}^{-1}$ are associated to stretching frequency of $\mathrm{N}-\mathrm{H}$, deformation frequency of $\mathrm{N}-\mathrm{H}$ and stretching frequency of $\mathrm{N}-\mathrm{C}$, respectively. The sorption peaks of $\mathrm{Li}-\mathrm{O}$ and $\mathrm{Fe}-\mathrm{O}$ were seemed at the wavelengths of $1300 \mathrm{~cm}^{-1}$ and $700 \mathrm{~cm}^{-1}$, respectively [23].

Plot of identified phase $\mathrm{mGO}$ is shown in Fig. S1. The X-ray diffraction (XRD) pattern of UreaLiCl-mGO is plotted in Fig. 2a. The diffraction peaks at $30.70^{\circ}, 35.97^{\circ}, 43.74^{\circ}, 53.94^{\circ}, 57.55^{\circ}$ and 63.32 ${ }^{\circ}$ characterized magnetite $\mathrm{Fe}_{3} \mathrm{O}_{4}$ (JCPDS cards No. 01-075-0449). Carbon structure was identified regarding peaks at $11.23^{\circ}, 21.64^{\circ}, 30.70^{\circ}, 35.97^{\circ}, 43.74^{\circ}, 53.94^{\circ}, 57.55^{\circ}, 63.32^{\circ}$ and $75.08^{\circ}(\mathrm{JCPDS}$ cards No. 01-079-1715). The comparison between XRD patterns of $\mathrm{mGO}$ and UreaLiCl-mGO displays that the process of modification has no consequence on $\mathrm{mGO}$ purity and structure. The broad peaks are related to the presence of UreaLiCl. According to the Scherrer formula (Equation 1), the crystal size of the total product decreased from $17 \mathrm{~nm}$ to $6 \mathrm{~nm}$, due to applying ultrasonic waves in the process of preparation [13].

$d(\stackrel{0}{A})=\frac{k \lambda}{\beta \operatorname{Cos} \theta}$ (Eq. 1)

In this formula, $\lambda$ is wavelength of incident beam (1.5406 $\AA$ ), $\beta$ is FWHM of peak in radian, $\theta$ is diffraction angle and $\mathrm{k}$ is the Scherrer constant (0.9).

Nanographs of mGO and of UreaLiCl-mGO are illustrated in Fig. 2b and Fig. 2c, respectively. Magnetic nanoparticles of $\mathrm{Fe}_{3} \mathrm{O}_{4}$ are structured as nanosphericals. $\mathrm{Fe}_{3} \mathrm{O}_{4}$ nanoparticles are located onto $\mathrm{GO}$ sheets homogenously and no agglomeration is detected, approving well-controlled conditions of synthesis including $\mathrm{pH}$, time and amount of materials. In addition, DES covers $\mathrm{mGO}$ completely. The morphology of $\mathrm{Fe}_{3} \mathrm{O}_{4}$ is unchanged but ultrasonic waves decreased the average size of particles from $50 \mathrm{~nm}$ to about 27 $\mathrm{nm}$ [13].

AGFM curve of UreaLiCl-mGO is plotted in Fig. 2d. Saturation magnetization (Ms) of nanocomposite is about \pm 25 electromagnetic units $\left(\mathrm{emu} \mathrm{g}^{-1}\right)$. This amount is more than the minimum magnetic amount 
$\left( \pm 16 \mathrm{emu} \mathrm{g}^{-1}\right)$ of magnetic adsorbent [24]. Meantime the component has superparamagnetic property.

\subsection{Optimization of the method}

\subsubsection{Effect of $\mathrm{pH}$}

$\mathrm{pH}$ is one of the effective parameters on adsorption process. In alkaline $\mathrm{pH}$, heavy metals form oxo or hydroxo complexes with $\mathrm{OH}^{-}$and in acidic $\mathrm{pH}, \mathrm{H}^{+}$ions occupy the active negative sites of adsorbents. In both condition the affinity of adsorbents to adsorb heavy metals decreases. To investigate the effect of $\mathrm{pH}, \mathrm{pH}$ of a series of samples was adjusted from 2 to 9 and the procedure was applied according to section 2.4. The results are plotted in Fig. 3. From $\mathrm{pH}=4$ to $\mathrm{pH}=6$, the recovery stayed maximum. Before $\mathrm{pH}=4, \mathrm{H}^{+}$occupied the active sites of adsorbent and after $\mathrm{pH}=6, \mathrm{~Pb}(\mathrm{II})$ ions were precipitated as $\mathrm{Pb}(\mathrm{OH})_{2}$ and $\mathrm{PbO}$, so recovery decreased. All subsequent works for separation and preconcentration of $\mathrm{Pb}(\mathrm{II})$ were done in $\mathrm{pH}$ of $5 \pm 0.5$.

\subsubsection{Effect of equilibrium time and amount of adsorbent}

The effect of contact time on $\mathrm{Pb}(\mathrm{II})$ adsorption onto UreaLiCl-mGO was investigated at different intervals in the range of one to 30 minutes. After gathering UreaLiCl-mGO by a magnet, the supernatant was removed and the settlement was eluted by $\mathrm{HNO}_{3}\left(1 \mathrm{~mL}, 2 \mathrm{~mol} \mathrm{~L}^{-1}\right)$. The recoveries are steady after 15 minute so it was selected as the optimum agitation time for all the subsequent experiments.

A series of UreaLiCl-mGO ranging from $1.0 \times 10^{-2} \mathrm{~g}$ to $5.0 \times 10^{-2} \mathrm{~g}$ was tested and $1.0 \times 10^{-2} \mathrm{~g}$ provided satisfying recovery in $\mathrm{Pb}$ (II) preconcentration. Low amount of the adsorbent confirms high affinity of UreaLiCl-mGO toward $\mathrm{Pb}(\mathrm{II})$ adsorption.

\subsubsection{Selecting the best eluent and time of desorption}

Elution step was optimized by investigating type and volume of eluents (Table 1). By increasing $\mathrm{HNO}_{3}$ concentration, the adsorption efficiency increased and $\mathrm{HNO}_{3}$ of 2 mol. $\mathrm{L}^{-1}$ was selected as the best eluent. Adsorbent collapsed in the presence of $\mathrm{HCl}$, which is related to its negative consequence on $\mathrm{Fe}_{3} \mathrm{O}_{4}$ and DES. Meantime, $0.5 \mathrm{~mL}, 1 \mathrm{~mL}, 1.5 \mathrm{~mL}$ and $2 \mathrm{~mL}$ of $\mathrm{HNO}_{3}$ were tested and $0.5 \mathrm{~mL}$ was optimized volume of eluent.

Table 1 Effect of eluent type $(1 \mathrm{~mL})$ on the preconcentration recovery of $\mathrm{Pb}^{2+}(\mathrm{n}=3)$

Adsorption conditions: $\mathrm{T}=25^{\circ} \mathrm{C}, \mathrm{C}_{0}=5.0 \times 10^{-5} \mathrm{~g} \cdot \mathrm{L}^{-1}, \mathrm{~V}=50 \mathrm{~mL}, \mathrm{pH}=5 \pm 0.5$, amount of sorbent $=1.0 \times$ $10^{-2} \mathrm{~g}$, adsorption time $=30 \mathrm{~min}$, desorption time $=5 \mathrm{~min}$. 


\begin{tabular}{|ll|}
\hline Recovery (\%) & Eluent \\
\hline $67.57 \pm 0.03$ & $\mathrm{HNO}_{3}\left(1 \mathrm{~mol} \mathrm{~L}^{-1}\right)$ \\
\hline $98.94 \pm 0.12$ & $\mathrm{HNO}_{3}\left(2 \mathrm{~mol} \mathrm{~L}^{-1}\right)$ \\
\hline $96.52 \pm 0.09$ & $\mathrm{HNO}_{3}\left(5 \mathrm{~mol} \mathrm{~L}^{-1}\right)$ \\
\hline $34.38 \pm 0.18$ & $\mathrm{HCl}\left(1 \mathrm{~mol} \mathrm{~L}^{-1}\right)$ \\
\hline $27.29 \pm 0.28$ & $\mathrm{HCl}\left(2 \mathrm{~mol} \mathrm{~L}^{-1}\right)$ \\
\hline $7.04 \pm 0.16$ & $\mathrm{HCl}\left(5 \mathrm{~mol} \mathrm{~L}^{-1}\right)$ \\
\hline
\end{tabular}

Effect of desorption time was tested in the range of 1 - 5 minutes in room temperature. After 3 minutes, the recovery was maximum, so 4 minutes was selected as the optimum desorption time.

\subsection{Swelling property of UreaLiCl-mGO}

UreaLiCl-mGO $\left(1.0 \times 10^{-2} \mathrm{~g}\right)$ was added into a solution of $\mathrm{Pb}$ (II) $\left(50 \mathrm{~mL}, 50 \times 10^{-6} \mathrm{~g} \mathrm{~L}^{-1}\right)$ at pH of $5 \pm 0.5$. After 15 minutes shaking, the UreaLiCl-mGO was collected by an external magnetic and weighted. The swollen ratio $(\mathrm{g} / \mathrm{g})$ was calculated according to Equation 2:

$$
W=\frac{W_{s}-W_{d}}{W_{d}} \text { (Eq. 2) }
$$

$\mathrm{W}$ (swelling ratio at time $\mathrm{t}$ ), $\mathrm{W}_{\mathrm{s}}$ (weight of swollen UreaLiCl-mGO) and $\mathrm{W}_{\mathrm{d}}$ (weight of dry UreaLiCl-mGO) are $6.6,7.0 \times 10^{-2} \mathrm{~g}$ and $1.0 \times 10^{-2} \mathrm{~g}$, respectively. The ion adsorption causes swelling of adsorbent, illustrating high affinity of UreaLiCl-mGO to adsorb $\mathrm{Pb}(\mathrm{II})[10,25]$.

\subsection{Reusability and durability of UreaLiCl-mGO}

In order to check the reusability of UreaLiCl-mGO, several consecutive preconcentration cycles of $\mathrm{Pb}$ (II) were examined according to general procedure. No significant variation was recorded up to seven cycles; however, preconcentration recovery decreased after this cycle. This weakness is related to the negative effect of $\mathrm{HNO}_{3}$ onto the adsorbent. $\mathrm{H}^{+}$ions occupy the sites of adsorbent, which decrease the tendency of the adsorbent toward $\mathrm{Pb}(\mathrm{II})$.

Oxidation of magnetic adsorbents is one limit in MSPE method, which confines the applicability of magnetic adsorbents to a short time after their preparation. This feature is named durability and could be achieved by repeating the preconcentration procedure during several days. The performance of the adsorbent was checked during 6 months and the recovery has no important changes. During these months, the adsorbent was kept at room condition and preconcentration procedure was conducted as mentioned, which confirms stability of UreaLiCl-mGO against oxidation. This resistibility is related to presence of DES, which prevents $\mathrm{Fe}_{3} \mathrm{O}_{4}$ nanoparticles from collapse. 


\subsection{Effect of interference ions and selectivity of UreaLiCl- $\mathrm{mGO}$}

$\mathrm{Pb}$ (II) could be adsorbed onto UreaLiCl-mGO via electrostatic interaction, which is not a selective force and may be affected in the presence of other metals [23]. In addition, some onions and $\mathrm{Pb}$ (II) may form complexes, and decline the preconcentration ability of UreaLiCl-mGO. This feature was tested in the presence of various concentrations of different cations and anions in test solutions of $\mathrm{Pb}$ (II) $(50 \mathrm{~mL}, 5.0 \times$ $10^{-5} \mathrm{~g} \mathrm{~L}^{-1}$ ). The signals were compared with that of a solution containing only $\mathrm{Pb}(\mathrm{II})$ and recoveries were in the range of $95-105 \%$. In concentration levels higher than those usually present in real samples, the method was not impaired (Table 2).

Table 2 The effect of interfering ions on recovery of $\mathrm{Pb}^{2+}$ preconcentration $(\mathrm{n}=3)$

\begin{tabular}{|lll|}
\hline Ions & Ratio of coexisting ions & $\begin{array}{l}\text { Recovery } \\
(\%)\end{array}$ \\
\hline $\mathrm{Na}(\mathrm{I})$ & 10000 & $97.12 \pm 0.02$ \\
\hline $\mathrm{K}(\mathrm{I})$ & 10000 & $101.65 \pm 0.05$ \\
\hline $\mathrm{Ca}(\mathrm{II})$ & 800 & $98.48 \pm 0.19$ \\
\hline $\mathrm{Mg}(\mathrm{II})$ & 700 & $97.19 \pm 0.08$ \\
\hline $\mathrm{Cd}(\mathrm{II})$ & 50 & $99.19 \pm 0.11$ \\
\hline $\mathrm{Cr}(\mathrm{II})$ & 600 & $96.10 \pm 0.16$ \\
\hline $\mathrm{Pd}(\mathrm{II})$ & 300 & $100.03 \pm 0.21$ \\
\hline $\mathrm{Zn}(\mathrm{II})$ & 100 & $101.27 \pm 0.09$ \\
\hline $\mathrm{Al}(\mathrm{III})$ & 500 & $102.49 \pm 0.09$ \\
\hline $\mathrm{Co}(\mathrm{II})$ & 20 & $99.98 \pm 0.13$ \\
\hline $\mathrm{Cu}(\mathrm{II})$ & 30 & $100.27 \pm 0.17$ \\
\hline $\mathrm{Ni}(\mathrm{II})$ & 100 & $98.17 \pm 0.14$ \\
\hline $\mathrm{SO}_{4}{ }^{2-}$ & 1000 & $101.48 \pm 0.27$ \\
\hline $\mathrm{Cl}^{-}$ & 200 & $104.25 \pm 0.15$ \\
\hline $\mathrm{NO}_{3}{ }^{-}$ & 1000 & $99.59 \pm 0.09$ \\
\hline $\mathrm{CO}_{3}{ }^{2-}$ & 2000 & $100.19 \pm 0.16$ \\
\hline
\end{tabular}


Selectivity was checked via comparing the performances of UreaLiCl-mGO to adsorb $\mathrm{Pb}$ (II) $\left(5.0 \times 10^{-5} \mathrm{~g}\right.$ $\left.\mathrm{L}^{-1}\right)$ and other heavy metals $\left(5.0 \times 10^{-5} \mathrm{~g} \mathrm{~L}^{-1}\right)$ at the same time (Table 3$)$. The ground reason for selective adsorption of $\mathrm{Pb}(\mathrm{II})$ onto Urea LiCl-mGO is their strong interaction in comparison with interactions of other heavy metals. Due to the small ionic radius of $\mathrm{Pb}(\mathrm{II})$, this ion has high charge density and is a hard ion; accordingly, it occupies the negative sites of adsorbent stronger and faster.

Table 3 Selectivity on the preconcentration of $\mathrm{Pb}^{2+}$

\subsection{Sample analysis}

\begin{tabular}{|ll|}
\hline Ions & $\begin{array}{l}\text { Recovery } \\
(\%)\end{array}$ \\
\hline $\mathrm{Cd}(\mathrm{II})$ & $80.45 \pm 0.11$ \\
\hline $\mathrm{Cr}(\mathrm{II})$ & $84.36 \pm 0.04$ \\
\hline $\mathrm{Cu}(\mathrm{II})$ & $90.25 \pm 0.08$ \\
\hline $\mathrm{Mn}(\mathrm{II})$ & $10.30 \pm 0.16$ \\
\hline $\mathrm{Pb}(\mathrm{II})$ & $95.45 \pm 0.21$ \\
\hline $\mathrm{Pd}(\mathrm{II})$ & $40.35 \pm 0.18$ \\
\hline $\mathrm{Zn}(\mathrm{II})$ & $76.35 \pm 0.10$ \\
\hline
\end{tabular}

Four different seed oils including sesame, hemp, sunflower seeds and grapeseed were tested as real samples. The preparation method of samples was expressed in section of sample preparation. The concentrations of the analyte were determined in both the spiked and unspiked samples according to the following equation.

$$
R \%=\frac{C_{1}-C_{2}}{C_{3}} \times 100 \text { (Eq. 3) }
$$

Where, $\mathrm{C}_{1}, \mathrm{C}_{2}, \mathrm{C}_{3}$ and $\mathrm{R} \%$ are spiked portion, unspiked portion, the concentration of the analyte and relative recovery, respectively. According to data, the method is highly applicable to preconcentrate $\mathrm{Pb}(\mathrm{II})$ in seed oil (Table 4).

Table 4 Analytical results of $\mathrm{Pb}^{2+}$ determination onto UreaLiCl-mGO $(\mathrm{n}=3)$ 


\begin{tabular}{|c|c|c|c|}
\hline Sample & $\begin{array}{l}\text { Spiked } \\
\left(\mathrm{g} \mathrm{L}^{-1}\right)\end{array}$ & Found & $\begin{array}{l}\text { Recovery } \\
(\%)\end{array}$ \\
\hline Sesame & 0 & 1.32 & - \\
\hline & $1.0 \times 10^{-5}$ & 11.56 & 102.10 \\
\hline & $5.0 \times 10^{-5}$ & 53.76 & 104.75 \\
\hline & $15 \times 10^{-5}$ & 148.56 & 98.17 \\
\hline Hemp & 0 & 5.37 & - \\
\hline & $1.0 \times 10^{-5}$ & 14.96 & 97.33 \\
\hline & $5.0 \times 10^{-5}$ & 52.67 & 95.12 \\
\hline & $15 \times 10^{-5}$ & 152.67 & 98.26 \\
\hline Sunflower Seeds & 0 & 2.56 & - \\
\hline & $1.0 \times 10^{-5}$ & 11.95 & 95.14 \\
\hline & $5.0 \times 10^{-5}$ & 48.56 & 95.11 \\
\hline & $15 \times 10^{-5}$ & 152.76 & 100.13 \\
\hline Grapeseed Oil & 0 & 0.7 & - \\
\hline & $1.0 \times 10^{-5}$ & 10.56 & 98.69 \\
\hline & $5.0 \times 10^{-5}$ & 50.85 & 100.29 \\
\hline & $15 \times 10^{-5}$ & 152.76 & 101.36 \\
\hline
\end{tabular}

\subsection{Analytical figures of merit}

Under optimal conditions, LDR (Fig. S2), LOD, LOQ, RSD and PF are $5.0 \times 10^{-6}-23 \times 10^{-5} \mathrm{~g} \mathrm{~L}^{-1}, 99 \times$ $10^{-8} \mathrm{~g} \mathrm{~L}^{-1}, 33 \times 10^{-7} \mathrm{~g} \mathrm{~L}^{-1}, 1.3 \%$ and 100 , respectively. Respective data are provided in electronic supplementary materials (ESM).

UreaLiCl-mGO is compared with some new adsorbents (Table 5). UreaLiCl-mGO has significant improvements in adsorbent amount, RSD and LDR. Additionally, UreaLiCl-mGO is applicable in semineutral $\mathrm{pH}$, which decreases the usage amount of solutions to $\mathrm{pH}$ adjustment. More importantly, UreaLiCl$\mathrm{mGO}$ is a green, safe and earth-friendly adsorbent.

Table 5 Comparison of analytical features of the SPE method in present research and several reported method for determination of $\mathrm{Pb}^{2+}$ (FAAS was used for all detections) 


\begin{tabular}{lllllll} 
Method & $\begin{array}{l}\text { Amount } \\
(\mathrm{g})\end{array}$ & LOD & RSD & PF & LDR & Reference \\
& $\left(\mathrm{g} \mathrm{L}^{-1}\right)$ & $(\%)$ & & $\left(\mathrm{g} \mathrm{L}^{-1}\right)$ & \\
\hline SPE & $12 \times 10^{-3}$ & $1.71 \times 10^{-6}$ & 1.81 & 110 & $8 \times 10^{-6}-500 \times 10^{-6}$ & {$[26]$} \\
\hline SPE & - & $0.025 \times 10^{-6}$ & 1.6 & 125 & $0.08 \times 10^{-6}-16 \times 10^{-6}$ & {$[27]$} \\
\hline MSPE & $150 \times 10^{-3}$ & $0.28 \times 10^{-6}$ & 1.6 & 90 & $1 \times 10^{-6}-500 \times 10^{-6}$ & {$[28]$} \\
\hline SPE & - & $0.13 \times 10^{-6}$ & 3.7 & 150 & $63 \times 10^{-6}-500 \times 10^{-6}$ & {$[29]$} \\
\hline SPE & $60 \times 10^{-3}$ & $6.5 \times 10^{-6}$ & 2.5 & 50 & $20 \times 10^{-6}-120 \times 10^{-6}$ & {$[30]$} \\
\hline MSPE & $1.0 \times 10^{-2}$ & $99 \times 10^{-8}$ & 1.3 & 100 & $5.0 \times 10^{-6}-23 \times 10^{-5}$ & This work
\end{tabular}

\subsection{Adsorption isotherm}

Adsorption isotherm investigates the amounts of analyte adsorbed per unit mass of adsorbent and the nature adsorption of analyte onto adsorbent [31]. According to Fig. S3a, by increasing the initial concentration of adsorbate, the amount of $\mathrm{Pb}(\mathrm{II})$ taken by unit mass of UreaLiCl-mGO increased. Four different isotherm models including Langmuir (Fig. S3b), Freundlich (Fig. S3c), Temkin (Fig. S3d) and Dubinine-Radushkevich (Fig. S3e) were considered to investigate the adsorption model [31, 32]. Freundlich, a model of multilayer adsorption, is fitted with the system (Table S1). Respective data are given in Electronic Supplementary Materials.

\subsection{Adsorption kinetic}

The relation between time and adsorption of $\mathrm{Pb}$ (II) onto UreaLiCl-mGO is investigated through kinetic of adsorption. Two models of Pseudo-First-Order (Fig. S4a) and Pseudo-Second-Order (Fig. S4b) were studied (Table S2). The Pseudo-First-Order model is fitted with the system. The pseudo-first-order kinetics equation describes the adsorption in solid-liquid systems based on the sorption capacity of solids. It assumes that one ion is adsorbed onto one unoccupied adsorption site on the UreaLiCl-mGO [33, 34]. Respective data are given in Electronic Supplementary Materials (ESM).

\subsection{Adsorption thermodynamic}

The relation between temperature and adsorption of $\mathrm{Pb}(\mathrm{II})$ onto UreaLiCl-mGO is studied through thermodynamic of adsorption. The temperature has positive effect onto adsorption capacity of UreaLiClmGO (Fig. S5a). The positive values of $\Delta \mathrm{H}$ and $\Delta \mathrm{S}$ show endothermic nature of adsorption and more agitation in sample solution. Negative values of $\Delta \mathrm{G}$ confirm spontaneous adsorption of $\mathrm{Pb}$ (II) onto UreaLiCl-mGO $[35,36]$. The calculated data are achieved according to Fig. S5b. They are summarized in Table S3. Respective data are given in Electronic Supplementary Materials (ESM).

\section{Conclusion}


This article investigated the applicability of a DES of Urea and $\mathrm{LiCl}$, loaded onto mGO to preconcentrate trace amounts of $\mathrm{Pb}(\mathrm{II})$. The preparation method is safe, quick, green and facile and the reagents are inexpensive and accessible; accordingly, the method is environmentally-friendly and energy efficient. The characterizations were conducted via FT-IR, XRD, SEM and AGFM. The swelling property was investigated. The optimum condition is $\mathrm{pH}$ of $5 \pm 0.5$, adsorbent dose of $1.0 \times 10^{-2} \mathrm{~g}$, adsorption time of 15 minutes, eluent of $\mathrm{HNO}_{3}$ and desorption time of 4 minutes. $\mathrm{Pb}(\mathrm{II})$ was quantified by a FAAS. LOD ( $99 \times$ $\left.10^{-8} \mathrm{~g} \mathrm{~L}^{-1}\right), \operatorname{LOQ}\left(33 \times 10^{-7} \mathrm{~g} \mathrm{~L}^{-1}\right), \operatorname{RSD}(1.3 \%), \operatorname{PF}(100)$ and LDR $\left(5 \times 10^{-6}-23 \times 10^{-5} \mathrm{~g} \mathrm{~L}^{-1}\right)$ confirm practical applicability of UreaLiCl-mGO to $\mathrm{Pb}(\mathrm{II})$ preconcentration. Selectivity and effect of interference ions were successfully checked. The adsorbent is reusable for seven cycles and durable for six months. Freundlich isotherm is the best fitted isotherm model and kinetic adsorption follows pseudo-first order model. The Thermodynamic parameters clear that the adsorption is endothermic and spontaneous and it happens through physisorption. Seed oils were successfully applied as real samples.

\section{Declarations}

\section{Acknowledgment}

Support for this study by the Research Council of the University of Tehran through grants is gratefully acknowledged.

\section{References}

1. M. Setoodehkhah, S. Momeni, Water Soluble Schiff Base Functinalized $\mathrm{Fe}_{3} \mathrm{O}_{4}$ Magnetic NanoParticles as a Novel Adsorbent for the Removal of $\mathrm{Pb}$ (II) and $\mathrm{Cu}$ (II) Metal lons from Aqueous Solutions. J. Inorg. Organomet. Polym Mater. 28(3), 1098-1106 (2018)

2. O.N. de Almeida, R.M. Menezes, L.S. Nunes, V.A. Lemos, F.H.M. Luzardo, F.G. Velasco, Conversion of an invasive plant into a new solid phase for lead preconcentration for analytical purpose. Environ. Technol. Innov. 21, 101336 (2021)

3. E. Koosha, M. Shamsipur, F. Salimi, M. Ramezani, A microextraction method based on precipitation for the simultaneous separation and preconcentration of cadmium and lead before their determination by FAAS: experimental design methodology. Sep. Sci. Technol. 56(10), 1721-1729 (2021)

4. M. Dana, P. Jamshidi, F. Shemirani Acid Brown-14 preconcentration onto an adsorbent consisting of $\mathrm{Fe}_{3} \mathrm{O}_{4}$, carbon nanotube and $\mathrm{CeO}$ : optimized by a multi-variable method. Res. Chem. Intermed. 47(3), 1021-1032 (2021)

5. G.I. Dzhardimalieva, I.E. Uflyand, Design Strategies of Metal Complexes Based on Chelating Polymer Ligands and Their Application in Nanomaterials Science. J. Inorg. Organomet. Polym Mater. 28(4), 1305-1393 (2018) 
6. A. Massoud, H.H. Mahmoud, Evaluation of Hybrid Polymeric Resin Containing Nanoparticles of Iron Oxide for Selective Separation of In(III) from Ga(III). J. Inorg. Organomet. Polym Mater. 27(6), 18061815 (2017)

7. M. Asadi, S. Shahabuddin, A. Mollahosseini, J. Kaur, R. Saidur, Electrospun Magnetic Zeolite/Polyacrylonitrile Nanofibers for Extraction of PAHs from Waste Water: Optimized with Central Composite Design. J. Inorg. Organomet. Polym Mater. 29(4), 1057-1066 (2019)

8. H.L. Jiang, Q.B. Fu, M.L. Wang, L.M. Lin, R.S. Zhao, Determination of trace bisphenols in functional beverages through the magnetic solid-phase extraction with MOF-COF composite. Food Chem. 345, 128841 (2021)

9. P. Jamshidi, F. Shemirani, Adsorption/desorption of acid violet-7 onto magnetic $\mathrm{MnO}_{2}$ prior to its quantification by UV-visible spectroscopy: optimized by fractional factorial design. Res. Chem. Intermed. 46(10), 4403-4422 (2020)

10. F. Faryadras, S.M. Yousefi, P. Jamshidi, F. Shemirani, Application of magnetic graphene-based bucky gel as an efficient green sorbent for determination of mercury in fish and water samples. Res. Chem. Intermed. 46(4), 2055-2068 (2020)

11. R. Mohammadzadeh Kakhki, M. Bina, Dispersive Micro-solid Phase Extraction Based on $\mathrm{Co}_{3} \mathrm{O}_{4}$ Modified Nanoclinoptilolite for Fast Determination of Malachite Green in the Environmental Water Samples. J. Inorg. Organomet. Polym Mater. 30(7), 2475-2479 (2020)

12. E. Alzahrani, A.A. Shaltout, S.I. Ahmed, Z.K. Heiba, H.H. Wahba, Hydrothermal Synthesis, Anionic Dyes Preconcentration, and Energy Storage of Amino-Functionalized CuNPs Regenerated Chitosan Membrane. J. Inorg. Organomet. Polym Mater. 31(6), 2492-2500 (2021)

13. M. Hejazi Khah, P. Jamshidi, F. Shemirani, Applicability of an eco-friendly deep eutectic solvent loaded onto magnetic graphene oxide to preconcentrate trace amount of indigotin blue dye. J. Mol. Liq. 342, 117346 (2021)

14. M. Galehassadi, S. Pourreza, Base and Catalyst-Free Preparation of Silyl Ethers in the Choline Chloride/Urea Deep Eutectic Solvent (DES). J. Inorg. Organomet. Polym Mater. 29(2), 541-549 (2019)

15. Y. Zhang, Y. Meng, L. Ma, H. Ji, X. Lu, Z. Pang, C. Dong, Production of biochar from lignocellulosic biomass with acidic deep eutectic solvent and its application as efficient adsorbent for $\mathrm{Cr}(\mathrm{VI})$. J. Clean. Prod. 324, 129270 (2021)

16. N. Rahmati, M. Rahimnejad, M. Pourali, S.K. Muallah, Effective removal of nickel ions from aqueous solution using multi-wall carbon nanotube functionalized by glycerol-based deep eutectic solvent. Colloids Interface Sci. Commun. 40, 100347 (2021)

17. M. Karimi, A.M.H. Shabani, S. Dadfarnia, Deep eutectic solvent-mediated extraction for ligand-less preconcentration of lead and cadmium from environmental samples using magnetic nanoparticles. Microchim. Acta 183(2), 563-571 (2016)

18. M. Ezoddin, N. Lamei, F. Siami, k Abdi, M.A. Karimi, Deep Eutectic Solvent Based Air Assisted Ligandless Emulsification Liquid-Liquid Microextraction for Preconcentration of Some Heavy 
Metals in Biological and Environmental Samples. Bull. Environ. Contam. Toxicol. 101(6), 814-819 (2018)

19. N. Lamei, M. Ezoddin, K. Abdi, Air assisted emulsification liquid-liquid microextraction based on deep eutectic solvent for preconcentration of methadone in water and biological samples. Talanta. 165 , 176-181 (2017)

20. T.G. Kazi, H.I. Afridi, M. Bhatti, A. Akhtar, A rapid ultrasonic energy assisted preconcentration method for simultaneous extraction of lead and cadmium in various cosmetic brands using deep eutectic solvent: A multivariate study. Ultrason. Sonochem. 51, 40-48 (2019)

21. M. Alvand, F. Shemirani, Fabrication of $\mathrm{Fe}_{3} \mathrm{O}_{4} @$ @graphene oxide core-shell nanospheres for ferrofluidbased dispersive solid phase extraction as exemplified for $\mathrm{Cd}(\mathrm{II})$ as a model analyte. Microchim. Acta 183(5), 1749-1757 (2016)

22. M. Alvand, F. Shemirani, Preconcentration of trace cadmium ion using magnetic graphene nanoparticles as an efficient adsorbent. Microchim. Acta 181(1-2), 181-188 (2014)

23. P. Jamshidi, M. Alvand, F. Shemirani, Magnetic $\mathrm{Mn}_{2} \mathrm{O}_{3}$ nanocomposite covered with $\mathrm{N}, \mathrm{N}$ bis(salicylidene)ethylenediamine for selective preconcentration of cadmium(II) prior to its quantification by FAAS. Microchim. Acta 186(8), 487 (2019)

24. Z. Ma, Y. Guan, H. Liu, Synthesis and characterization of micron-sized monodisperse superparamagnetic polymer particles with amino groups. J. Polym. Sci. A: Polym. Chem. 43(15), 3433-3439 (2005)

25. J. Zhang, L. Wang, A. Wang, Preparation and Properties of Chitosan-g-poly(acrylic acid)/Montmorillonite Superabsorbent Nanocomposite via in Situ Intercalative Polymerization. Ind. Eng. Chem. Res. 46(8), 2497-2502 (2007)

26. V.O. Vasylechko, G.V. Gryshchouk, M.I. Kaminska, B.M. Stel'makhovych, A solid-phase extraction method using acid-modified Transcarpathian clinoptilolite for preconcentration of trace amounts of lead in water samples. Appl. Nanosci. 9(5), 1057-1065 (2019)

27. A.S. Gugushe, A. Mpupa, P.N. Nomngongo, Ultrasound-assisted magnetic solid phase extraction of lead and thallium in complex environmental samples using magnetic multi-walled carbon nanotubes/zeolite nanocomposite. Microchem. J. 149, 103960 (2019)

28. A. Tunçeli, A. Ulaş, O. Acar, A.R. Türker, Solid Phase Extraction of Cadmium and Lead from Water by Amberlyst 15 and Determination by Flame Atomic Absorption Spectrometry. Bull. Environ. Contam. Toxicol. 102(2), 297-302 (2019)

29. A. Jouki, S. Rastegarzadeh, M. Zendehdel, B. Zargar, Application of vortex-assisted solid-phase extraction for the simultaneous preconcentration of $\mathrm{Cd}(\mathrm{II})$ and $\mathrm{Pb}(\mathrm{II})$ by nano clinoptilolite modified with 5(p-dimethylaminobenzylidene) rhodanine. Anal. Methods. 11(31), 3996-4005 (2019)

30. Z. Erbas, M. Soylak, S. Ozdemir, E. Kilinc, $\mathrm{Fe}_{3} \mathrm{O}_{4} @ \mathrm{SiO}_{2} @$ Bacillus pumilis: magnetised solid phase bioextractor for preconcentration of $\mathrm{Pb}(\mathrm{II})$ and $\mathrm{Cu}(\mathrm{II})$ from water samples. Int. J. Environ. Anal. Chem. 99(11), 1112-1122 (2019) 
31. P. Jamshidi, F. Shemirani, Adsorption and desorption of $\mathrm{Pb}^{2+}$ on magnetic $\mathrm{Mn}_{2} \mathrm{O}_{3}$ as highly efficient adsorbent: Isotherm, kinetic and thermodynamic studies. Colloids Surf. A Physicochem. Eng. Asp. 571, 151-159 (2019)

32. M. Verma, I. Tyagi, V. Kumar, S. Goel, D. Vaya, H. Kim, Fabrication of $\mathrm{GO}-\mathrm{MnO}_{2}$ nanocomposite using hydrothermal process for cationic and anionic dyes adsorption: Kinetics, isotherm, and reusability. J. Environ. Chem. Eng. 9(5), 106045 (2021)

33. A. Chowdhury, S. Kumari, A.A. Khan, M.R. Chandra, S. Hussain, Activated carbon loaded with Ni-Co-S nanoparticle for superior adsorption capacity of antibiotics and dye from wastewater: Kinetics and isotherms. Colloids Surf. A Physicochem. Eng. Asp. 611, 125868 (2021)

34. A. Hashem, M.A. Sanousy, L.A. Mohamed, P.U. Okoye, B.H. Hameed, Natural and Low-Cost P. turgidum for Efficient Adsorption of $\mathrm{Hg}(\mathrm{II})$ lons from Contaminated Solution: Isotherms and Kinetics Studies. J. Polym. Environ. 29(1), 304-312 (2021)

35. D. Balarak, M. Zafariyan, C.A. Igwegbe, K.K. Onyechi, J.O. Ighalo, Adsorption of Acid Blue 92 Dye from Aqueous Solutions by Single-Walled Carbon Nanotubes: Isothermal, Kinetic, and Thermodynamic Studies. Environ. Process. 8(2), 869-888 (2021)

36. P. Sirajudheen, P. Karthikeyan, K. Ramkumar, P. Nisheetha, S. Meenakshi, Magnetic carbon-biomass from the seeds of Moringa oleifera@ $\mathrm{MnFe}_{2} \mathrm{O}_{4}$ composite as an effective and recyclable adsorbent for the removal of organic pollutants from water. J. Mol. Liq. 327, 114829 (2021)

\section{Figures}




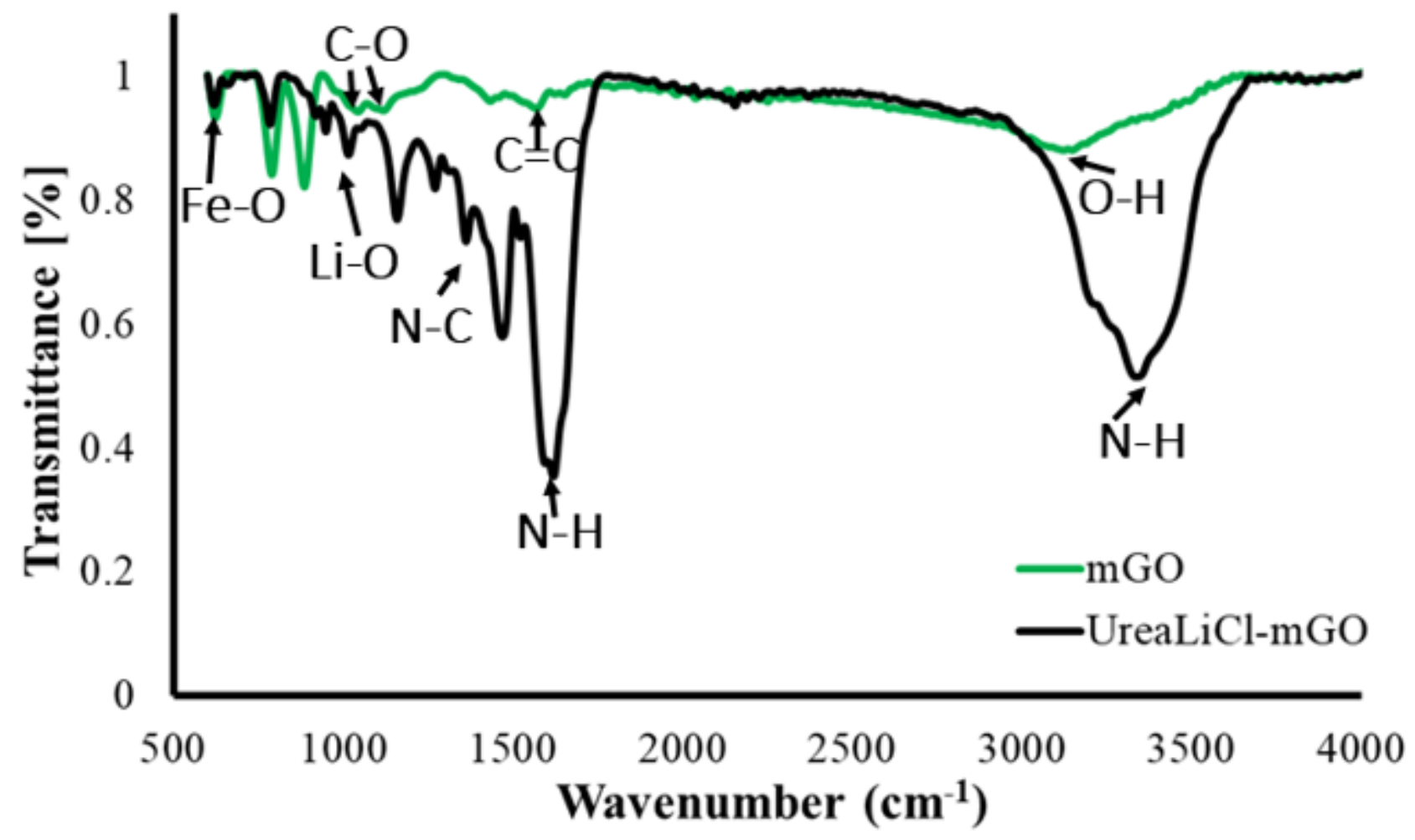

Figure 1

FT-IR spectra of $\mathrm{mGO}$ and UreaLiCl-mGO 

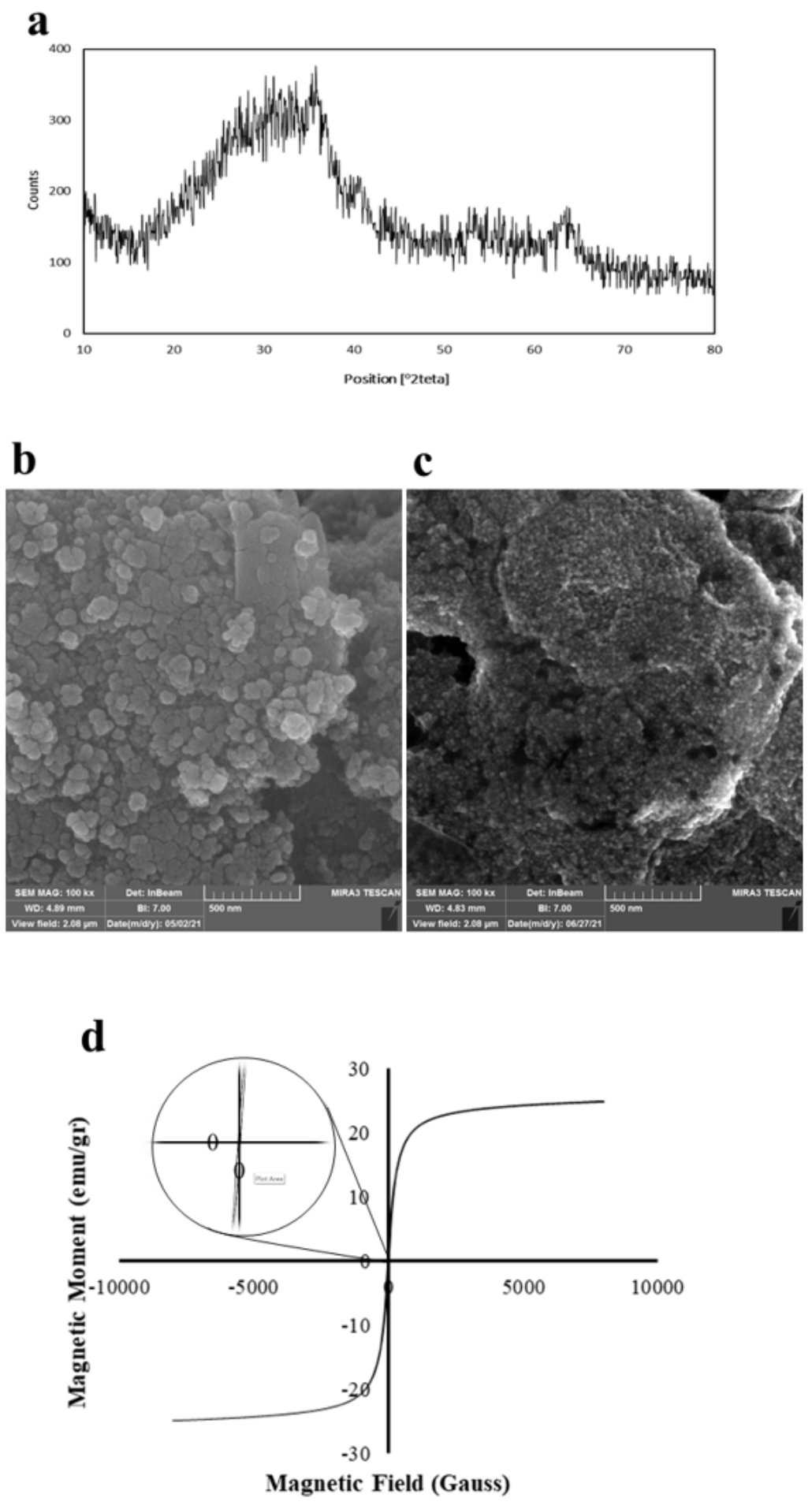

Figure 2

a The XRD pattern of UreaLiCl-mGO, b The SEM image of mGO, c The SEM image of UreaLiCl-mGO and $d$ Magnetic hysteresis loops image of UreaLiCl-mGO 


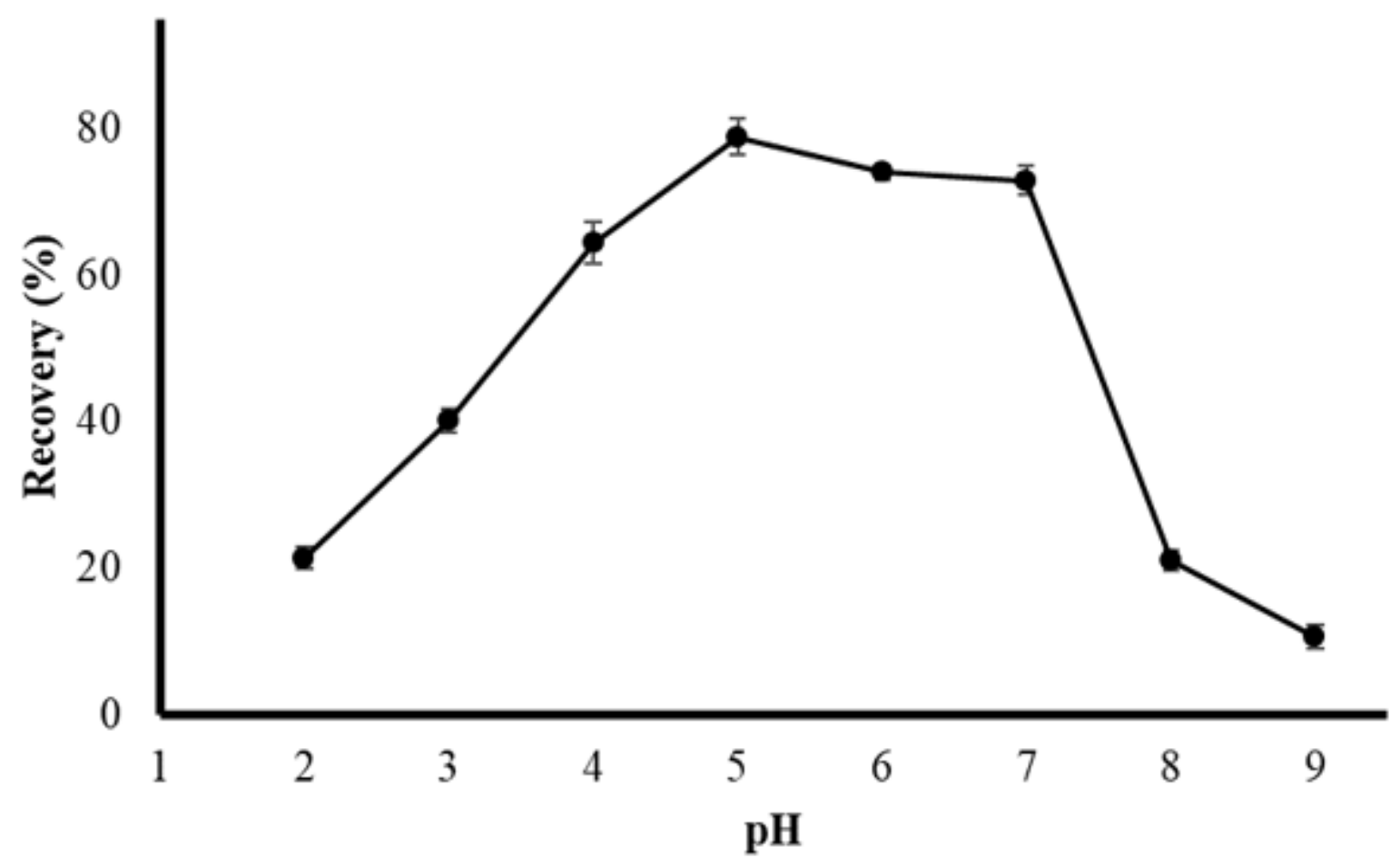

Figure 3

Influence of $\mathrm{pH}$ on adsorption of $\mathrm{Pb} 2+$ onto UreaLiCl-mGO $(\mathrm{n}=3)$ Adsorption conditions: $\mathrm{T}=25^{\circ} \mathrm{C}, \mathrm{CO}=$ $5.0 \times 10-5 \mathrm{~g} \cdot \mathrm{L}-1, \mathrm{~V}=50 \mathrm{~mL}$, amount of sorbent $=5.0 \times 10-2 \mathrm{~g}$, adsorption time $=30$ minutes, desorption time $=5$ minutes and eluent $=1 \mathrm{~mL}$ of $1 \mathrm{~mol} \mathrm{~L}-1 \mathrm{HNO}$.

\section{Supplementary Files}

This is a list of supplementary files associated with this preprint. Click to download.

- ElectronicSupplementaryMaterial.docx 